Original article

Received: 1 March 2017 / Accepted: 9 November 2017

\title{
MAPPING OF POLAR AREAS BASED ON HIGH-RESOLUTION SATELLITE IMAGES: THE EXAMPLE OF THE HENRYK ARCTOWSKI POLISH ANTARCTIC STATION
}

\author{
Zdzisław Kurczyński, Sebastian Różycki, Paweł Bylina
}

Faculty of Geodesy and Cartography, Warsaw University of Technology

\begin{abstract}
To produce orthophotomaps or digital elevation models, the most commonly used method is photogrammetric measurement. However, the use of aerial images is not easy in polar regions for logistical reasons. In these areas, remote sensing data acquired from satellite systems is much more useful. This paper presents the basic technical requirements of different products which can be obtain (in particular orthoimages and digital elevation model (DEM)) using Very-High-Resolution Satellite (VHRS) images. The study area was situated in the vicinity of the Henryk Arctowski Polish Antarctic Station on the Western Shore of Admiralty Bay, King George Island, Western Antarctic. Image processing was applied on two triplets of images acquired by the Pléiades $1 A$ and $1 B$ in March 2013. The results of the generation of orthoimages from the Pléiades systems without control points showed that the proposed method can achieve Root Mean Squared Error (RMSE) of 3-9 $\mathrm{m}$. The presented Pléiades images are useful for thematic remote sensing analysis and processing of measurements. Using satellite images to produce remote sensing products for polar regions is highly beneficial and reliable and compares well with more expensive airborne photographs or field surveys.
\end{abstract}

Keywords: polar regions, satellite images, VHRS, orthophoto, georeferencing, geolocation

\section{Introduction}

Rapid and complex environmental processes have recently been taking place in polar regions. These areas are particularly sensitive to changes and disturbances resulting from human activities (Chwedorzewska and Korczak, 2010; Wódkiewicz et al., 2013) as well as climatic changes (Chwedorzewska, 2009). Antarctic Treaty data report that more than 100 stations, refuges and field camps operate in Antarctica in the winter, inhabited approximately 1,000 personnel, the summer staff is usually four times more numerous (www.comnap.aq). Every year, researchers working in 
Antarctica produce a huge amount of geodata (data from a specified geographic location). The conventional means of visualizing such data is with reference to terrain objects projected onto topographic maps.

The study of complex ecosystems and mutual relations between existing processes requires access to data and tools which allow spatial analyses and investigations of the dynamics of existing processes. A conventional map presents reality in a static way, as a specified group of phenomena, but this is not sufficient for modern multidisciplinary research. Nowadays, geoinformation databases are created instead of maps.

The usefulness of such databases depends on the quantity and quality of stored geoinformation. Among this data, particular attention should be paid to topographic objects, which create the natural background and serve as the reference for other, "sectorial" data.

An effective source of geoinformation is aerial photographs (Crawley and Aston, 2006). After photogrammetric processing, such images become conventional topographic maps or topographic databases, which form the raw data input for GIS systems. Such photographs are the source not only of survey data, but - after interpretation - also descriptive data about objects and processes within a given area.

However, acquisition of aerial photographs in polar conditions meets serious barriers, e.g., distance, lack of airports, weather limitations, and huge costs (Roscoe, 2013). An alternative source is satellite images, which have been available since the 1970s. Due to low resolution, for many years such images were more useful for interpretation at the global scale than for creating maps of local coverage.

The appearance of VHRS (Very-High-Resolution Satellite) systems, with resolution close to aerial images, caused a shift in the conventional approach to the roles of aerial and satellite photographs (Kocaman et al., 2006). The latter became the perfect source of geoinformation data in polar regions.

Satellite data have since played, an important role in research in polar regions. Satellite images are used to monitor glacial changes (Arigony et al., 2006), snow cover and ice dynamics (Rueckamp et al., 2010), as well as to estimate physical properties of lentic water bodies (Vogt and Braun, 2004), morphological transformations and the geographical distribution of moraines (Rosa et al., 2014).

Vogt and Braun (2004) emphasize the need to use the latest satellite systems with improved spatial and spectral resolution, as these allow a more detailed assessment of the influence of snow cover on the ice-free ecosystems of King George Island and environmental monitoring. This has become especially true in the last two years, since new VHRS systems have come online.

\section{The characteristics of VHRS systems}

The terms "VHRS systems" or "one-metre systems" are used to define imaging resolution of approximately $1 \mathrm{~m}$ or lower (the ground pixel size, Tab.1).

After some unsuccessful attempts to put VHRS into orbit, the long-awaited breakthrough was made on 24 September 1999 when the Ikonos-2 was launched (Capderou, 2006), becoming the first commercial system delivering images with onemetre pixels. On 18 October 2001, a second one-metre satellite system was successfully put into orbit, QuickBird-2, collecting data with a pixel size of $0.61 \mathrm{~m}$. In June 2003 the Orbimage company successfully put the OrbView-3 into orbit (Lein, 2012), which became the third one-metre imaging system. Thus, geoinformation 
entered the era of commercially available, high-resolution satellite images. The increasing supply of data resulted in an improved offer of services as well as the reduction of costs.

These systems differ in details, but have many common features which substantially affect their usability and distinguish them from previous systems (Kurczyński, 2014):

1. The systems are launched into circular, heliosynchronized orbits, i.e., tilted from the plane of the equator at an angle of about $98^{\circ}$. They are polar orbits (tilted about $8^{\circ}$ from the poles); the angles between orbit planes and the direction of the Sun are constant over time. This means the satellite transition over the given area is always at the same local time, and, as a consequence, the same collection of images is obtained in comparable illumination conditions (with the same Sun azimuth).

2. The orbit trajectory and camera orientation elements have high frequency and accuracy. The achieved measurement precision of these elements (called the image geolocation accuracy) at a certain accuracy level allows images to be processed without knowing any measured points (ground control points).

3. The imaging systems are based on an electro-optical scanner. The array of CCD detectors (charge-coupled device) is mounted in the focal plane of the optical system (Knödel et al., 2007), registering the image line perpendicularly to the orbit direction. The image is continuously registered in the orbit direction, due to the satellite movement. The resolving power is determined by the altitude, the focal length of the optical system and the size of detector lines. This resolving power is characterized by the ground sampling distance.

4. Usually, the following elements are mounted in the focal plane: the line of detectors which register data in the visible range; the panchromatic mode (PAN) and lines of detectors which register data in narrow, spectral subranges, usually red, green, blue (RGB) and infrared; and the multispectral mode (MS). As a rule, the resolution achieved in the multispectral mode is worse - the pixel is usually four times bigger (Tab. 1).

5. The systems are characterized by high radiometric resolution, i.e., the ability to distinguish surface objects' reflectance values. This ability depends on "dynamic range". For example, 11-bit range means the ability to distinguish 2,048 grey levels (as compared to conventional images, which have a ca. sixbit range, corresponding to 64 levels of grey).

6. The optical system can be tilted in the big angular range forward, backward, and also sideways. This means that data for a relatively narrow imaging strip are collected from the wide strip of terrain over which the satellite is passing. It is of significant importance for the system operability that the imaging session from a given orbit can be "programmed" to provide images of areas of interest - though only such areas which are not currently covered by clouds. The ability to tilt the system sideways greatly shortens "re-visit period", i.e., the period between consequent imaging opportunities of the same area on the Earth's surface.

7. The ability to tilt the optical system forward and backward enables so-called "one-orbit stereoscopy". The system collects the data for a given area twice: firstly in tilting the system forwards, and secondly in tilting it backwards, with a delay of several dozen seconds (see Fig. 1a). The resulting stereopair is characterized by very good conditions for height measurements. This type of stereoscopy has an advantage over the stereoscopy "from neighbouring 
orbits" (applied in the older SPOT-1, $-2,-3$, and -4 satellites) where stereo images were obtained by tilting the system sideways and imaging from two orbits. However, there is a problem with repeat orbits: good weather conditions must prevail on both dates. This reduces the chances of good stereoscopy.

An alternative solution is to image more than one terrain strip in one orbit. This allows the width of the terrain strip images to be significantly increased during a single satellite pass. This is illustrated in Fig. $1 \mathrm{~b}$.

8. The commercial operators assume further systems will be put into orbit, extending the systems' lifetime. These will be accompanied by an efficient network of image distribution, radically reducing data access time for users. There is a wide offer of image-processing cartographic products with diverse resolutions and geometric accuracies (http://www.e-geos.it). Usually, archival images are significantly cheaper and their value is hard to overestimate for establishing the dynamics of processes taking place in the studied areas.

a)

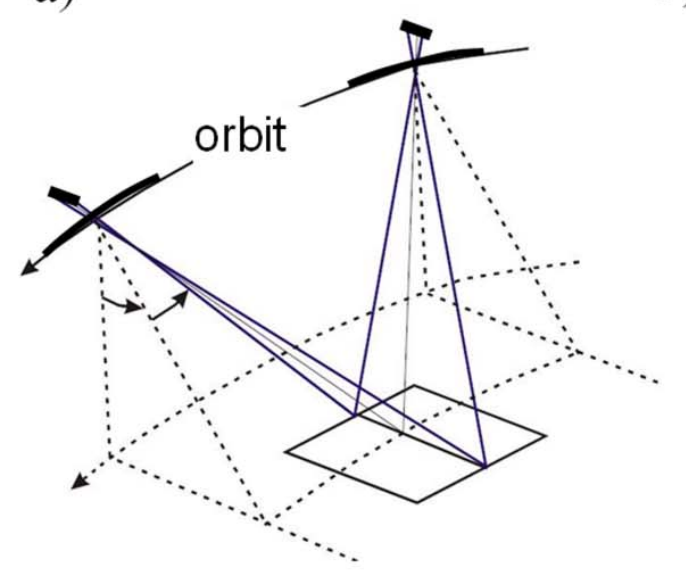

b)

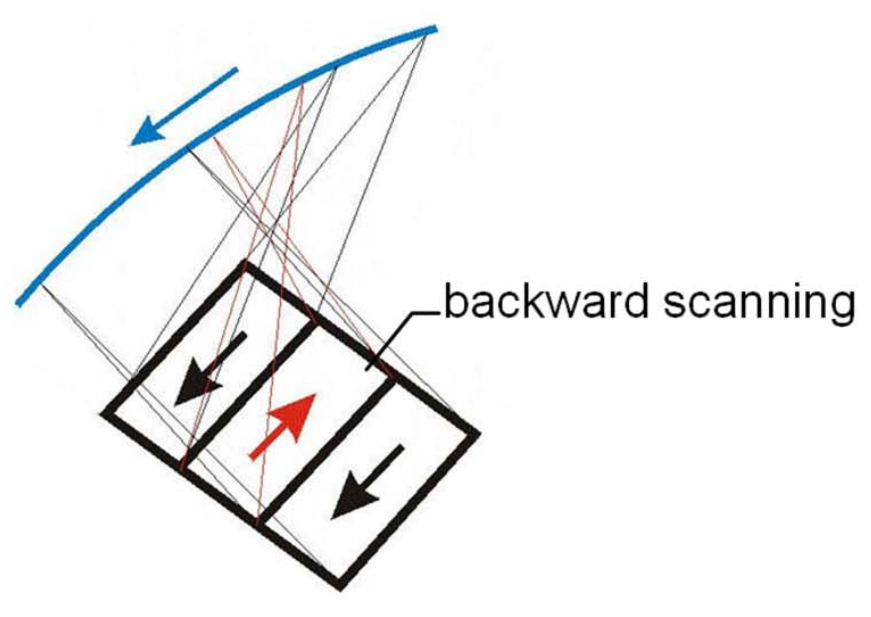

Fig. 1. Scanning modes.

Left: stereoscopic imaging from one orbit with deflection optical system along and across orbit; right: combining the scanning directions "forwards" and "backwards" in a single satellite pass to image a few strips forming a block (e.g., Ikonos system) 


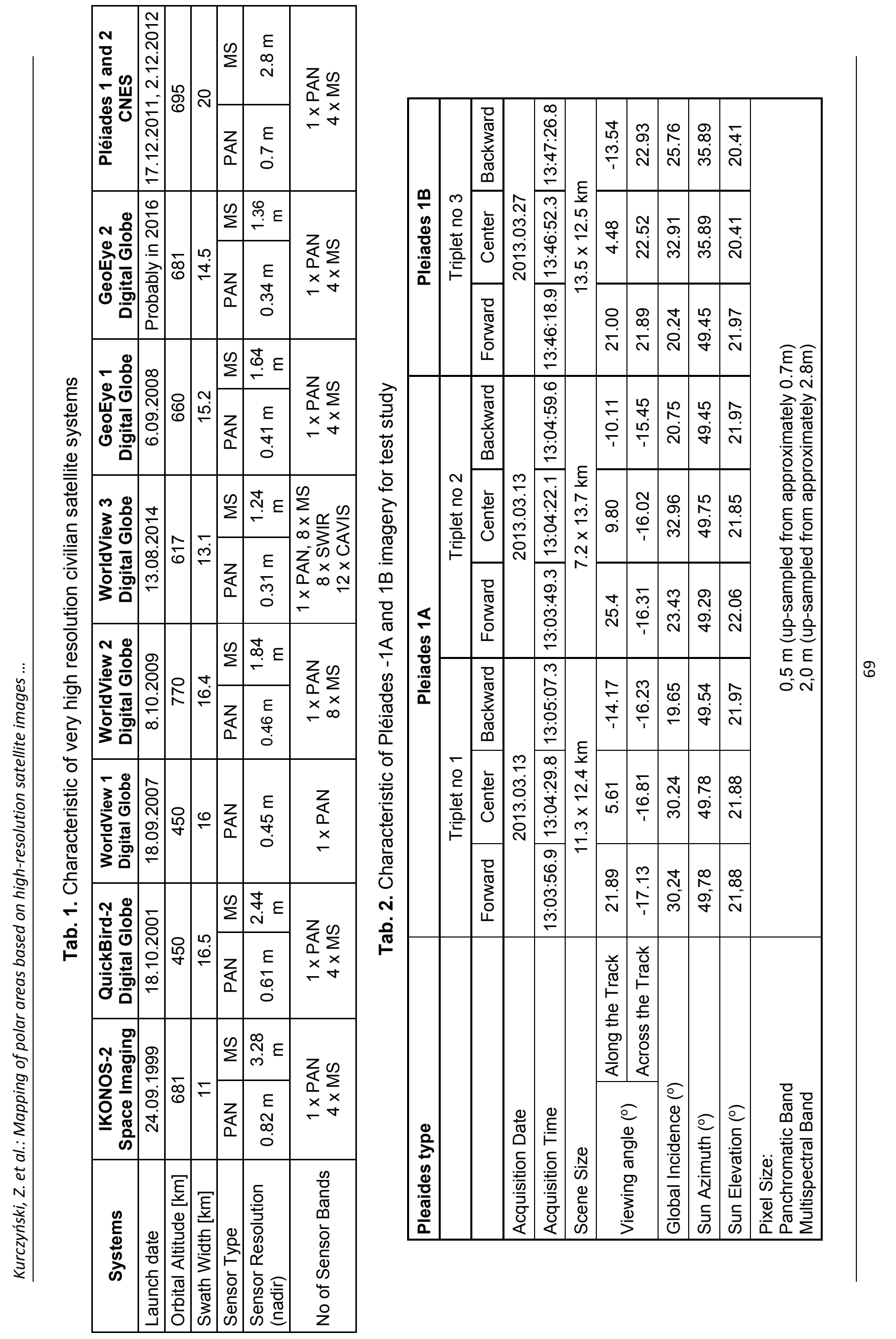


In the first decade of the $21^{\text {st }}$ century the US government's National GeospatialIntelligence Agency (NGA), a successor of the National Imagery and Mapping Agency (NIMA), announced two large tenders for the development of the new generation of VHRS systems of $0.50 \mathrm{~m}$ ground resolution within the framework of satellite imaging development. As a result, the DigitalGlobe company built the WorldView, and Orbimage (now GeoEye) - the GeoEye systems. The two twin satellites of the French Pléiades programme may also be considered as a VHRS system (Tab.1). The new-generation VHRS systems differ from prior systems by:

- Higher resolving power. A pixel of panchromatic range is only about $0.5 \mathrm{~m}$ or even $0.3 \mathrm{~m}$ (WorldView-3);

- Higher number of spectral bands. WorldView-2 has eight spectral bands and WorldView-3 29 bands. The eight spectral bands of WorldView-2 include the "coastal" channel (range 423-453 nm) (Maglione et al., 2014). This channel was designed to penetrate shallow water bodies, and may be used for studies of coastal areas of polar regions.

- The WorldView-3 system has three scanners: an eight-band multispectral with $1.24 \mathrm{~m}$ ground resolution, visible and near-infrared range (similar to WorldView-2); an eight-band mid-infrared-range SWIR with $3.7 \mathrm{~m}$ ground resolution and a 12band CAVIS (Clouds, Aerosols, Vapors, Ice and Snow) with $30 \mathrm{~m}$ ground resolution (Barazzetti et al., 2016). The multiplicity of spectral bands is of particular importance for remote sensing studies of polar regions.

- Higher geolocation accuracy, i.e., the determination of image location in a field coordinate system with the use of on-board sensors. This accuracy has been increased from 15-25 $\mathrm{m}$ (for the first VHRS systems) to approx. $3 \mathrm{~m}$ (for VHRS systems of the new generation) (Poli et al., 2013). It determines the imageprocessing accuracy, for example in the form of an orthophotomap, which may be obtained without field measurements.

\section{Other systems of satellite imagery}

Besides VHRS systems, newer satellites of the Landsat and SPOT systems are actually on orbits. Their pixel size is lower but the imaging swath is significantly wider. Landsat-8 provide imaging in a 180-km-wide strip and in 11 spectral bands, including two thermal bands (Ullamnn et al., 2016).

SPOT 6 and 7 are twin satellites in orbits shifted by $180^{\circ}$, which reduces the revisit time to one day. These orbits are similar to the orbits of Pléiades 1 and 2 . The imaging swath is $60 \mathrm{~km}$ with five spectral bands, and the ground resolution is $1.5 \mathrm{~m}$ (PAN) and $6 \mathrm{~m}$ (MS) (Perko et al., 2014).

Products of high-resolution systems

Typical products of high-resolution satellite systems include:

- "Raw" images, usually after initial geometric and radiometric corrections. Such images, amended based on the camera geometric model and orbit parameters, may be used for further processing, such as creation of orthophotomaps, or for automatic image classification. In the case of stereoscopic images, it is possible to generate a digital terrain model (DTM) or to perform stereo digitizing (e.g. spatial surveys for creation of vector maps).

- Orthorectified images, processed to the specified cartographic projection, for the specified ellipsoid. Individual images may be mosaicked to create a continuous image of a bigger area. 
Such products may be created as panchromatic mode or colour images, through the multispectral mode (MSI). If the system operates in the RGB and infrared bands, it is possible to generate a colour image with similarity to real colours (coordinating the red green and blue, bands) or a colour infrared image (coordinating the green, red and infrared bands).

The resolution capacity of multispectral images is usually worse than that of panchromatic images. Combinations of both products are commonly applied, resulting in a colour, pan-sharpened image (PSI). These are colour images whose pixel size is equal to the panchromatic images.

The most common products are orthorectified images. Besides the image itself, a digital terrain model (DTM) is also required to perform orthorectification. At present, the DTM terrain models of the moderate elevation accuracy can be accessed online free of charge. Good examples are the Shuttle Radar Topography Mission (SRTM) or ASTER satellite models. In some regions sufficiently high-resolution DTMs are currently lacking (for example the South Sandwich Islands). In this and other cases, VHRS satellite images are not orthorectified (Lynch et al., 2012).

Such data allow for generation of an orthoimage in the specified cartographic projection, with the same spatial resolution and scale of colours as the source images and a point location accuracy which corresponds to the geo-location accuracy of images without any terrain points. Assuming one or two ground control points (GCPs) (points of known field positions), a positioning accuracy of one pixel may be obtained (e.g. Fraser and Hanley, 2003; Barazzetti et al., 2016).

The ability to create an orthophotomap of such parameters is of great importance for mapping polar areas, where any field measurements may present serious logistical issues.

It should also be noted that cartographic processing of satellite images is not difficult; images and processing tools are easily available. In fact, this process is even easier than processing of aerial photographs.

Image processing of larger areas (larger than one satellite frame) requires the purchase of several satellite frames with small overlaps, which creates a "block" of images (Różycki, 2015). The regularity of a satellite's passing over an area of interest allows the time of image acquisition to be planned. Due to the weather limitations in polar regions, for example in terms of cloud cover and mist (Annasso et al., 2003), this is important to ensure ultimate success.

A digital orthophotomap can be used as a reference layer for the developed GIS system. It is the perfect readable background for entering and visualizing interesting objects and phenomena. According to existing needs, it is possible to transform the orthophotomap into the vector format simply by digitizing the visible objects.

\section{The Henryk Arctowski Polish Antarctic Station on Pléiades 1A and 1B satellite images}

The Pléiades system is composed of the twin satellites Pléiades $1 \mathrm{~A}$ and Pléiades $1 \mathrm{~B}$, which operate as a true constellation on the same orbit and are phased $180^{\circ}$ from each other. Added to their oblique viewing capability (up to a $45^{\circ}$ angle) and exceptional agility, this orbit phasing allows the satellites to revisit any point on the globe daily (Pléiades User Guide, 2012).

It is worth noting that Pléiades images are recorded with a high radiometric resolution (12-bit pixel depth). This means the possibility to distinguish 4096 grey 
levels. Other very-high-resolution sensors (like GeoEye or WorldView) have a pixel depth at acquisition of 11 bits, meaning that each pixel can take one value out of 2048; this means less capacity when distinguishing subtle nuances, especially at the beginning or the end of the spectrum (Tab 1.). According to the same principle, it will be easier to detect pale-coloured elements in very light/bright environments (e.g., sand, ice, nearly white ground), as more saturation problems are avoided (Pléiades User Guide, 2012).

A useful feature of Pléiades is that it offers high-resolution stereoscopic cover capability. The stereoscopic cover is achieved within the same pass of the area, which enables a homogeneous product to be created quickly. The system offers the possibility to achieve a "classical" stereoscopic imaging (like the GeoEye or WorldView systems), composed of two images the base-to-height ratio $(B / H)$ can be adjusted, but also stereoscopic imaging with an additional quasi-vertical image (tristereo), thus providing the user with both the image and its stereoscopic environment.

Thus, three images are ultimately acquired, that is, a triplet (the so-called, "tristereo mode") of the same area: one image with the camera facing forward, one in the vertical position, and one facing backward. The first and the third images produce a good stereoscopic effect, which is useful, for example, in creation of digital terrain models; the geometry of the second image is less influenced by the camera tilt angle and height differences. Even without further processing, the geometry of such images may be considered as very close to the cartographic projection of the final map.

The efficient manoeuvring (rotation) abilities of the satellites on the Pléiades orbit enables two triplets of images to be recorded during one passage.

Two sets of satellite images were acquired for the area of study. The first of them was acquired by the Pléiades 1A system on 13 March 2013; it consisted of two triplets of images (Fig. 2). The first triplet, with the "Arctowski" visible, did not cover the Western Shore of Admiralty Bay.

The triplet acquired on 27 March 2013 was also used; it covered the entire area of study (Fig. 3). Unfortunately, images from this set are characterized by cloud cover of 15-20\%. The surrounding areas are also partially covered by cloud.

The images were ordered in the "rawest" (most unprocessed), allowing for further processing. The raw image contains complete information concerning the camera geometric model and the orbit trajectory, stored in RPC (Rational Polynomial Functions) coefficients, supplied together with the image (Tab. 2).

\section{The assessment of georeference accuracy of acquired Pléiades images}

The geolocation accuracy of Pléiades images is assessed by the system administrator as $8.5 \mathrm{~m}$ for vertical imaging and $10.5 \mathrm{~m}$ for the camera tilted at $30^{\circ}$ from the vertical line (Pléiades User Guide, 2012). This relates to the declared accuracy of the image's connection to the field co-ordinate system, based on the RPC model supplied with the image. This accuracy of image processing may thus be achieved without any field points. This is important in the case of cartographic processing of images of polar regions. 

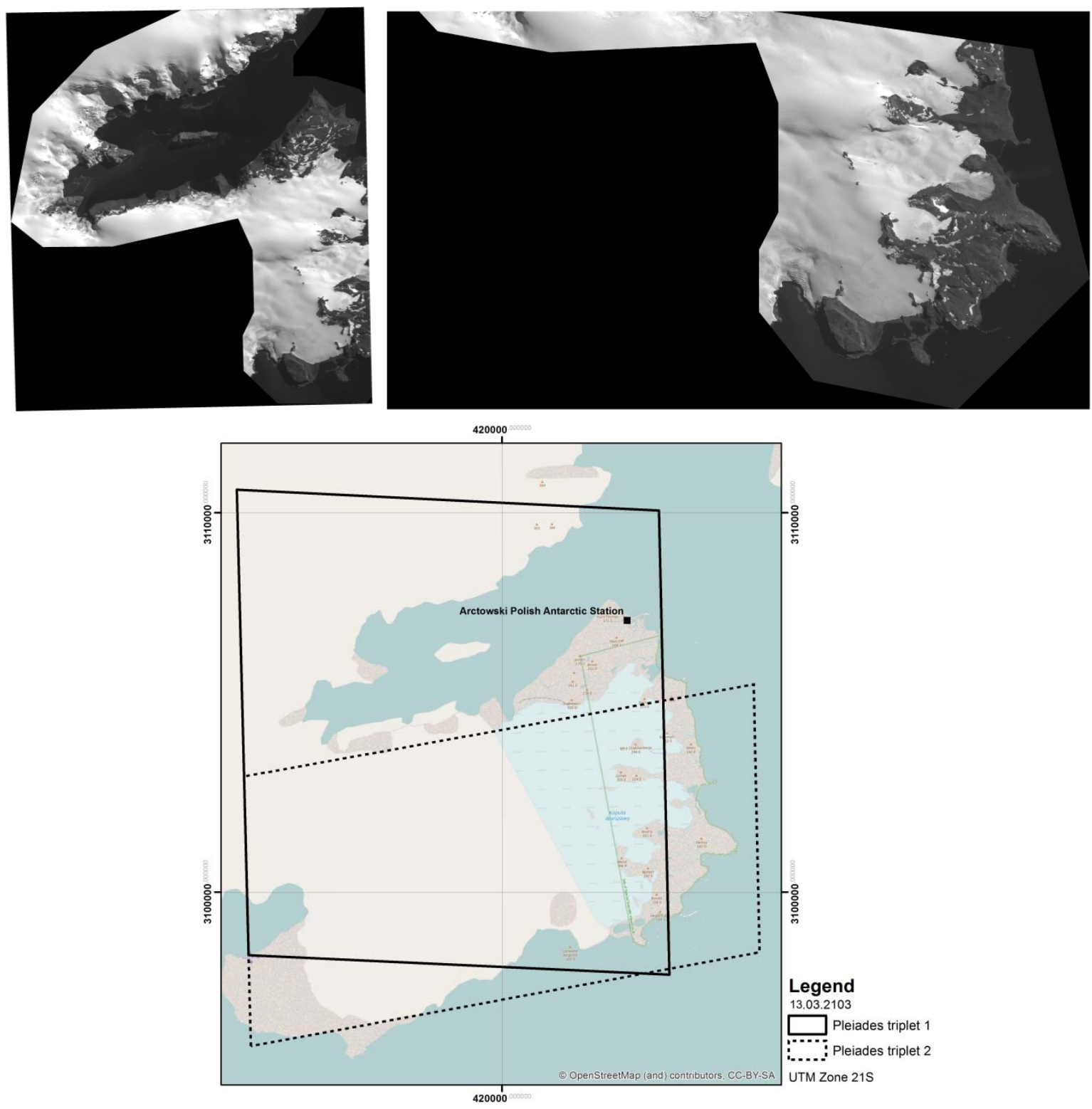

Fig. 2. Images taken by Pléiades $1 \mathrm{~A}$ on 13 March 2013. Left: triplet no. 1 - panchromatic image (not covering the Western Shore of Admiralty Bay); right: triplet no. 2 - panchromatic image (covering the missing fragment of the coast but without the Station). Below: location of Pléiades $1 \mathrm{~A}$ images on the Western Shore of Admiralty Bay, King George Island

(Source: Astri Poland, OpenStreetMap)

In order to confirm the above assumptions, it was decided to assess the real geolocation accuracy of analysed images. This was done by comparing the coordinates of a group of control points measured in the field with location measurements in the image, based on the RPC model only.

In the vicinities of the "Arctowski" the co-ordinates of nine conspicuous terrain features were measured, which were also identifiable in the images. The field coordinates were measured using the GPS technique. The measurements and image processing were performed with the use of the OrthoEngine $\mathrm{PCl}$ Geomatica software. 

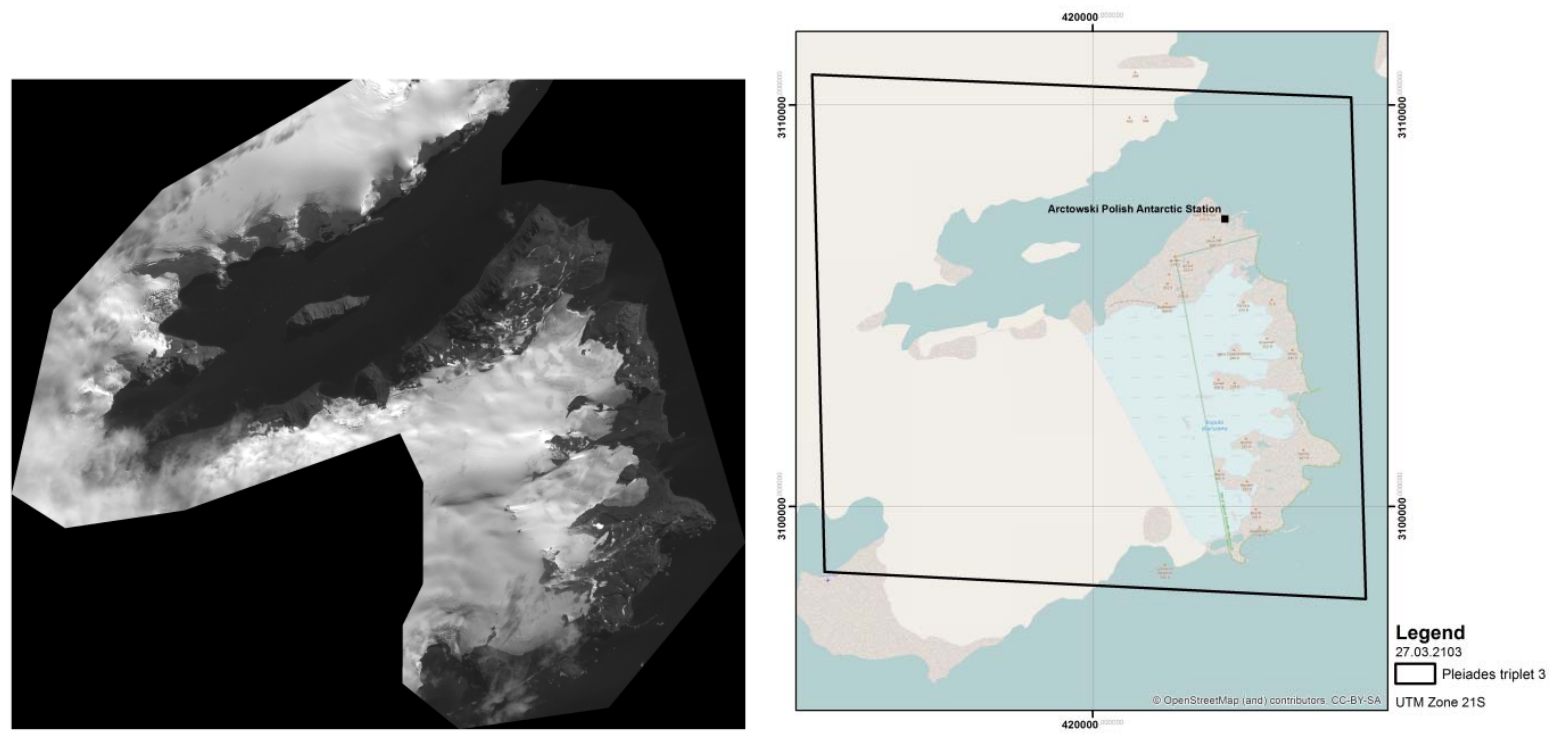

Fig. 3. Images taken by Pléiades 1B on 27 March 2013. Left: panchromatic image with $H$. Arctowski Station; right: location of image on the Western Shore of Admiralty Bay, King George Island (Source: Astri Poland, OpenStreetMap)

As a result, the following georeference accuracy of near-vertical images was obtained (mean errors of $X$ and $Y$ co-ordinates):

- Pléiades 1A image, triplet no. 1 (13 March 2013):

RMS $X=0.76 \mathrm{~m}, \mathrm{RMS} \mathrm{Y}=9.79 \mathrm{~m}$,

- Pléiades 1B image, triplet no. 3 (27 March 2013):

RMS $X=1.65 \mathrm{~m}, \mathrm{RMS} Y=1.61 \mathrm{~m}$.

It should be stressed that deformations which occur in the given image, determined for nine control points, were very similar with respect to their value and directions. It may also be seen that the achieved georeference accuracy of analysed images does not deviate from the Pléiades system accuracy, as declared by the system administrator.

\section{Possibilities of measurement processing of Pléiades images}

The presented Pléiades images of the Station are useful for thematic remote sensing analysis and processing of measurements. The following products of processing of measurements may be listed:

1. Development of the digital terrain model (DTM) based on the pair of stereoscopic images. This is automatically performed using image-matching techniques, which require the use of specialized software tools. In order to eliminate georeference errors, which can result in systematic errors in the elevations of the resulting DTM, knowledge of one or two ground points is required. The expected error of elevations of the resulting DTM will not exceed $1 \mathrm{~m}$.

2. The digital orthophotomap is the most typical result of VHRS image processing. The DTM is required to develop this product. The DTM accuracy depends on height differences in the imaged area and on the camera tilt angle (the bigger the tilt angle, the higher the influence of height differences and the required accuracy of the DTM). For nearly vertical camera orientation, i.e., in the case of the central image of a triplet, the influence of height differences may be neglected in practice. 
The expected topographic accuracy of the orthophotomap is similar to image geolocation accuracy. When using one or two ground points, the orthophotomap error may be reduced to approximately one pixel of the image resolution (i.e., approx. 0.5-0.7 $\mathrm{m}$ for the Pléiades system) (Poli et al., 2013; Perko et al., 2014; Postelniak, 2014). Figure 4 presents a fragment of an orthophotomap which covers the vicinities of "Arctowski", developed using the near-vertical image and the popular ArcGIS PRO software.

3. For the areas covered by more than one image, i.e., the small overlaps, the respective images may either be individually processed, or, even better, combined into a geometrically coherent block (Różycki, 2015). For this purpose, "tie points" are applied, i.e., points located in the mutual overlapping zones, which are used for connecting images. Connection of images in blocks allows the internal geometric coherence to be maintained while limiting the required total number of ground points. Implementation of this task requires the use of specialized software tools.



Fig. 4. Fragment of orthophotomap from Pléiades $1 \mathrm{~A}$ (13 March 2013) for Henryk Arctowski Polish Antarctic Station (figure without scale)

The resulting orthophotomap may be produced either in black and white, if it is based on a panchromatic image, or in colour, i.e., in real colours or in colour-infrared.

\section{Summary and conclusions}

Mapping of polar regions is relatively difficult. Methods based on the use of aerial photographs for the purposes of measurements are also difficult due to distances from airports and costs of aerial photogrammetric work. 
On the other hand, many researchers representing different scientific fields operate in these areas. They are interested in referencing results of studies to surrounding terrain features, i.e., the elements of topographic maps and modern topographic databases. With the use of contemporary GIS tools, such databases allow for implementation of interdisciplinary spatial analyses of areas of interest using the data acquired by groups of researchers.

VHRS images, which have been available for more than ten years, have a resolution similar to that of aerial photographs, which allows them to overcome the discussed difficulties and to create databases with location accuracy corresponding to large-scale topographic maps (1: 10,000 and larger scales), practically without fieldwork.

The images and processing methods are relatively easily accessible. This paper has discussed the basic technical requirements of different products which can be produced using VHRS images. These are illustrated using the orthophotomap of the vicinities of the Henryk Arctowski Polish Antarctic Station, produced using Pléiades images of a resolution of $0.5 \mathrm{~m}$ and location accuracy better than $10 \mathrm{~m}$, without any field surveys.

\section{Acknowledgements}

High-resolution Pléiades $1 \mathrm{~A}$ and $1 \mathrm{~B}$ images were acquired for the areas around the Henryk Arctowski Polish Antarctic Station and field measurements performed in the framework of the statutory research performed at the Faculty of Geodesy and Cartography of the Warsaw University of Technology. The authors thank the participants of these studies for making the images and GPS surveys available.

\section{References}

Annasso C., Santoleri R., Marullo S., \& Dortenzio F. (2003). Remote sensing of cloud cover in the Arctic region from AVHRR data during the ARTIST experiment. International Journal of Remote Sensing, vol.24, No.3, 437- 456

Arigony-Neto J., Saurer H., Jaña R., Rau F., Cardia Simões J., \& Goßmann H. (2006). Monitoring snow parameters on the Antarctic Peninsula using satellite data: A new methodological approach. EARSeL eProceedings, 5(1), 100-110

Barazzetti, L., Roncoroni, F., Brumana, R., Previtali, M. (2016). Georeferencing Accuracy Analysis of a Single WORLDVIEW-3 Image Collected Over Milan. ISPRS - International Archives of the Photogrammetry, Remote Sensing and Spatial Information Sciences, Volume XLI-B1, 2016, 429-434. http://dx.doi.org/10.5194/isprs-archives-XLI-B1-429-2016.

Capderou M. (2006). Satellites: Orbits and Missions, Springer Science \& Business Media.

Chwedorzewska, K. J., \& Korczak, M. (2010). Human impact upon the environment in the vicinity of Arctowski Station, King George Island, Antarctica. Polish Polar Research, 31(1), 45-60

Chwedorzewska K.J. (2009). Terrestrial Antarctic Ecosystems at the Changing World - an overview. Polish Polar Research 30, 263-273

Crawley, B., Aston, J. (2003). GIS for Sustainable Coastal Zone Management in the Pacific - A Strategy. Coastal and Marine Geo-Information Systems: Applying the Technology to the Environment. Springer Netherlands, 85-96. https://doi.org/10.1007/0-306-48002-6_6. 
Fraser C.S., Hanley H.B. (2003). Bias compensation in rational functions for Ikonos satellite imagery, Photogrammetric Engineering \& Remote Sensing, 69(1):53-57.

Knödel K., Lange G., Voigt H-J. (2007). Environmental Geology: Handbook of Field Methods and Case Studies. SPRINGER VERLAG GMBH, 1325 pp.

Kocaman S., Zhang I., Gruen A., \& Poli D. (2006). 3D city modeling from high resolution satellite images. In Proceedings of the ISPRS Conference Topographic Mapping From Space (With Special Emphasis on Small Satellites), 6 pp

Kurczyński Z. (2014). Fotogrametria. PWN, Warszawa

Lein J. (2012). Environmental Sensing: Analytical Techniques for Earth Observation. Springer-Verlag New York, 334p. https://doi.org/10.1007/978-1-4614-0143-8.

Lynch H., R. White A.D. Black, \& Naveen R. (2012). Detection, differentiation, and abundance estimation of penguin species by high-resolution satellite imagery. Polar Biology 35, 963-968

Maglione P., Parente C., Vallarioc A. (2014). Coastline extraction using high resolution WorldView-2 satellite imagery, European Journal of Remote Sensing, 47:1, 685-699, DOI: 10.5721/EuJRS2014473

Perko R., Raggam H., Gutjahr K. \& Schardt M. (2014). Assessment of the mapping potential of Pléiades stereo and triplet data. ISPRS Annals of Photogrammetry, Remote Sensing and Spatial Information Sciences, II-3, 103-109

Pléiades User Guide (2012). Astrium EADS, v. 2.0, 118pp

Poli D., Remondino F., Angiuli E. \& Agugiaro G. (2014). Radiometric and geometric evaluation of GeoEye-1. WorldView-2 and Pléiades-1A stereo images for 3D information extraction. ISPRS Journal Photogrammetry Remote Sensing. http://dx.doi.org/10.1016/j.isprsjprs.2014.04.007

Poli D., Remondino F., Angiuli E. \& Agugiaro G. (2013). Evaluation of Pléiades-1A triplet on Trento testfield. International Archives of the Photogrammetry, Remote Sensing Spatial Information Sciences, 40 (1/W1), 287-292

Postelniak A. (2014). Geometric Potential of Pleiades 1A satellite Imagery. Geosciences Engineering, Volume LX (3), 19-27

Roscoe, J. (2013). Antarctic Photogeography, in Antarctica in the International Geophysical Year: Based on a Symposium on the Antarctic (eds A.P. Crary, L.M. Gould, E.O. Hulburt, H. Odishaw \& W. E. Smith), American Geophysical Union, Washington D. C.. doi: 10.1029/GM001p0018

Rosa K.K., Souza E.J.R., Vieira R., \& Simões J.C. (2014). The landforms and patters of deglaciation of the Dragon glacier, King George Island, South Shetlands, Antarctica. Revisita de Geografia, 30, 6-16

Różycki S. (2015). Testing the influence of initial data on the georeference accuracy of a block of satellite images of the high spatial resolution. Oficyna Wydawnicza Politechniki Warszawskiej, Warszawa, PhD Thesis, 160pp

Rueckamp M. , Blindow N. , Suckro S. , Braun M., \& Humbert A. (2010). Dynamics of the ice cap on King George Island, Antarctica: field measurements and numerical simulations. Annals of Glaciology, 51 (55), 80-90

http://www.e-geos.it (ASI/Telespazio Company, accessed on 04 April 2015)

Ullmann T., Büdel C., Baumhauer R., Padashi M. (2016). Sentinel-1 SAR Data Revealing Fluvial Morphodynamics in Damghan (Iran). Amplitude and Coherence Change Detection. International Journal for Earth Science and Geophysics 2: 007

Vogt S. \& Braun M. (2004). Influence of Glaciers and Snow Cover on Terrestrial and Marine Ecosystems as Revealed by Remotely-Sensed Data. Revista de Pesquisa Antártica Brasileira, 4, 105-118 
Wódkiewicz M., Galera H., Chwedorzewska K. J., Giełwanowska I., Olech M. (2013). Diaspores of the Introduced Species Poa annua L. in soil samples from King George Island (South Shetlands, Antarctica). Antarct Arct Alp Res 45:415-419

\section{Authors:}

PhD, D.Sc. Zdzisław Kurczyński 1), z.kurczynski@gik.pw.edu.pl

PhD Sebastian Różycki ${ }^{1)}$, s.rozycki@gik.pw.edu.pl

PhD, D.Sc. Paweł Bylina 2), p.bylina@gik.pw.edu.pl

1) Warsaw University of Technology, Faculty of Geodesy and Cartography, Department of Photogrammetry, Remote Sensing and Spatial Information Systems

2) Warsaw University of Technology, Faculty of Geodesy and Cartography, Department of Spatial Management and Environmental Sciences 